\title{
How healthcare can help heal communities and the planet
}

\section{(C) $(\mathcal{\Theta} \Theta$ OPEN ACCESS}

The gains from healthcare are often undermined by the sector's contributions to social inequity and environmental damage, but it doesn't have to be that way argue Damon Francis and colleagues

\author{
Damon Francis chief clinical officer, Gary Cohen president and cofounder ${ }^{2}$, Jay Bhatt president ${ }^{3}$, \\ Charlotta Brask sustainability director ${ }^{4}$, Mahesh Devnani assistant professor ${ }^{5}$, Gael Surgenor director \\ of community and social innovation ${ }^{6}$
}

\begin{abstract}
${ }^{1}$ Health Leads, Oakland, CA, USA; ${ }^{2}$ Health Care Without Harm, Boston, MA, USA $;{ }^{3}$ Health Research and Educational Trust, Chicago, IL, USA ${ }^{4}$ Region Stockholm, Stockholm, Sweden; ${ }^{5}$ Department of Hospital Administration, Post Graduate Institute of Medical Education and Research, Chandigarh, India; ${ }^{6}$ Southern Initiative, Auckland Council, Auckland, New Zealand
\end{abstract}

Over the past few decades, the world has made substantial progress on health outcomes, with large improvements in life expectancy and childhood mortality and many breakthroughs in treatments. Although progress has not been evenly distributed, some of the biggest improvements have been in countries with the most difficult health challenges. ${ }^{1}$ At the same time, however, the healthcare sector is contributing to poor health by exacerbating social inequity and environmental damage, both of which are major factors in the growing burden of non-communicable diseases such as cardiovascular disease, chronic respiratory diseases, and diabetes. ${ }^{2-4}$

The 17 sustainable development goals (SDGs) adopted by world leaders in September 2015 recognise that human wellbeing depends on reducing social inequity and protecting the environment. A recent study showed that the global healthcare sector is critical to achieving the SDGs and the comprehensive vision of health behind them. ${ }^{5}$ It concluded that healthcare is the most important sector for achieving six of the 17 goals, including those related to poverty, education, and employment. Healthcare is also in the top three for another seven goals and is cited more often than any other sector. ${ }^{5}$

We consider how healthcare is harming social inequity and causing environmental damage and present examples of healthcare organisations that are working to achieve healthy people living in equitable and resilient communities on a sustainable planet.

\section{Sustainable energy and production}

Climate change has rapidly become a critical driver of global morbidity and mortality. The World Bank estimates that climate change could exacerbate existing health inequities by putting more than 100 million people back into extreme poverty by $2030 .{ }^{6}$ Another recent study conservatively estimates that climate change will increase mortality by $35 / 100000$ or 3.9 million lives a year by 2099 , with a much heavier toll on low income regions.

Although many countries have not done an extensive assessment of their health sectors' contributions to climate change, the NHS estimates that the health sector represents $39 \%$ of all public sector greenhouse gas emissions in England. ${ }^{3}$ In the US, healthcare contributes $9 \%$ of overall greenhouse gas emissions. ${ }^{2}$

Pollution and toxic waste rank alongside climate change as major threats to health and sustainability, particularly for low income communities. The World Bank estimates that $23 \%$ of child deaths among residents of India could be attributed to pollution, which means that about 350000 children aged under 5 years die every year as a result of bad air, contaminated water, or similar problems. ${ }^{8}$ Unfortunately, healthcare is an important contributor to morbidity and mortality from pollution. One study estimated that the indirect health burdens caused by emissions from the healthcare sector are commensurate with the health burden caused by preventable medical errors. ${ }^{9}$

Increasingly, healthcare organisations of all sizes are implementing strategies to limit their harmful environmental effects (box 1). By switching to renewable energy and reducing 
healthcare waste, healthcare organisations can reduce greenhouse gas emissions and pollution, contribute to growth in renewable energy employment, and realise large financial savings. ${ }^{10}$

\section{Box 1: Reducing greenhouse gas emissions}

\section{Gundersen Health System ${ }^{11}$}

This non-profit healthcare organisation based in Wisconsin, US, was $100 \%$ dependent on coal for electricity and $100 \%$ dependent on natural gas to heat its facilities in 2006. It recognised that reliance on fossil fuels added to local respiratory health problems and had a negative effect on the local economy as well as increasing the cost of delivering care. Gundersen set a goal to become the first health system in the US to be heated, cooled, and powered by renewable energy that it owned.

Over the next few years, it co-invested in a variety of community based clean energy projects. Guided by audits conducted by a local air conditioning company, Gundersen invested $\$ 2 \mathrm{~m}(£ 1.6 \mathrm{~m} ; € 1.8 \mathrm{~m})$ in efforts to reduce energy use and saved $\$ 1.2 \mathrm{~m}$ every year thereafter. Regional partners co-investing in two wind sites included a large private construction company and an organic farm cooperative.

As a collaborating partner, the local county government contributed gas from the local landfill, which Gundersen used to heat, power, and cool an outpatient campus with 1200 staff. It purchased previously unused hardwood chips from several local lumber mills to fuel a high tech biomass boiler providing heat, power, and sterilisation capability. Gundersen decreased its particulate and greenhouse gas emissions by over $90 \%$, saved money, and boosted the local economy. Each year the system has many days of energy independence and also provides a backstop for extreme weather events when the grid may fail.

These efforts also more deeply connected Gundersen with its community partners in the shared purpose of improving health and economic wellbeing, and serve as a model in the healthcare sector for addressing climate change. Region Stockholm ${ }^{12}$

A local health authority that is also one of Europe's largest healthcare providers, Region Stockholm has led several initiatives to tackle climate change and harmful healthcare waste. In 2004 it installed a pilot facility at Karolinska University Hospital that splits nitrous oxide-a commonly used gas in medicine that has 300 times the global warming impact of carbon dioxide and contributes to ozone depletion-into harmless nitrogen and oxygen. The facility was the first of its kind in the world, and the programme has since been extended to all hospitals within the region.

The region also works to reduce the emissions of active substances from the production of pharmaceuticals by requiring that its suppliers have implemented procedures to monitor and control harmful discharge and emissions.

Additionally, the council has incorporated data on the environmental effect of pharmaceuticals into the development of a drug formulary known as the Wise List, which has had the added benefit of reducing healthcare costs. The Wise List is primarily used by primary care providers in the Stockholm region, and adherence to the drug formulary is high. ${ }^{12}$

Healthy Families New Zealand ${ }^{13}$

Healthy Families was established by the New Zealand Ministry of Health to prevent chronic disease through a comprehensive and coordinated approach rooted in leadership of community residents. In Auckland, an urban area with about 1.6 million people, a collaborative initiative with the Sikh community to use waste land for food production and to create a food forest found that it is customary in the Sikh community to dispose of fabric used in religious rituals in incinerators, creating air pollution and greenhouse gas emissions. In partnership with Healthy Families and others, they developed a programme to share the fabric with communities who could reuse it. Since December 2017, women from Samoan, Tongan, Maori, and Cook Islands communities, together with other community based organisations in Auckland, have been creating upcycled products that provide additional income and the associated health benefits to hundreds of families. In addition to the community economic benefit, avoiding incineration or disposal in landfill prevents the equivalent of 3.6 tonnes of $\mathrm{CO}_{2}$ emissions a year, which is the equivalent of taking 2.5 cars off the road in Auckland. ${ }^{13}$

\section{Resilient food systems}

Agriculture and food production can damage the environment through extensive pesticide use and expose farmworkers to toxic chemicals that are linked to cancer, birth defects, and neurological damage. Unhealthy processed food has contributed to a large rise in obesity and non-communicable diseases around the world. Industrial meat production is an important contributor to antibiotic resistance, which in Europe causes morbidity and mortality of a similar scale to influenza, tuberculosis, and HIV combined, and is projected to substantially increase healthcare costs over the next decade. Many hospitals contribute to these problems, serving food that causes the same diseases they are treating through its low nutritional quality and unsustainable production methods. ${ }^{14-16}$

Some healthcare organisations are beginning to improve the food they serve their patients and the systems that produce that food. These organisations are treating "food as medicine"providing prescriptions for fruits and vegetables, teaching cooking classes, and integrating other creative approaches to healthy eating with clinical care. They are also leveraging their purchasing power to support local and sustainable agriculture in the communities they serve, modelling healthy food environments and contributing to healthier food systems and guaranteed markets for sustainable growers (box 2). ${ }^{17}$

\section{Box 2: Better food production}

\section{Vienna Hospital Association}

The Vienna Hospital Association is a group of 11 hospitals, nine geriatric centres, and six long term care homes in Vienna, Austria. It cares for 400000 inpatients and 3.5 million outpatients a year and serves 30000 patient meals a day. As part of Vienna's green procurement policy, more than $30 \%$ of all the ingredients in the food served across the hospital system are organic, and most of this food is sourced from local suppliers. It serves less meat and also provides tap water rather than bottled water.

The healthcare sector's food purchasing strategy is embedded in the city's climate action plan, which requires a $50 \%$ reduction in greenhouse gas emissions by 2020 for products procured. Through this integrated approach, the hospital system is taking better care of its patients, modelling healthy food environments in its facilities, supporting sustainable agriculture in the community, and reducing its climate footprint. ${ }^{17}$

\section{Healthy homes and neighbourhoods for all}

Where people live is perhaps the single most important determinant of their health. Stark disparities in health outcomes between neighbourhoods that are within walking distance of one another have been documented in high and low income countries because of inequitable distributions of power, money, and resources. ${ }^{18}$ Health hazards that originate within the home are a major cause of health problems. The hazards include injury; exposure to chemical substances, mould and damp, and pests and infestations; poor access to water and sanitation; proximity to pollution sources; and inadequate protection from extreme weather. ${ }^{19}$

Despite this, and the fact that focusing healthcare resources on neighbourhood based primary care can achieve remarkable results, much of the healthcare sector continues to concentrate its activities in hospitals and specialty care far removed from these places and issues. ${ }^{20}$ Global initiatives to increase investment in the community conditions that drive health outcomes have often been opposed by powerful interests, including some health insurers and health professional organisations. ${ }^{4}$

As healthcare organisations recognise that health is driven by home and neighbourhood contexts, they are applying new strategies that are centred outside clinics and hospitals and focus on root causes of disease, in some cases achieving short term financial benefits as well. These approaches are often led by patient organisations and community leaders and include local primary care as well as purchasing, hiring, and investment strategies that support improved health outcomes for disadvantaged communities (box 3). ${ }^{21} 22$ 


\section{Box 3: Healthy homes and neighbourhoods}

\section{Chagas Ecohealth ${ }^{23}$}

Chagas Ecohealth is a collaboration of community residents, health ministries, researchers, and others working to develop strategies to stop the spread of Chagas disease in central America using an approach rooted in local ecology and community driven problem solving. Worldwide, around 40000 new cases of Chagas disease occur each year, and in Guatemala alone, over four million people are at risk of transmission of the disease by triatomine insects ("kissing bugs").

Traditional approaches to preventing the transmission of Chagas relied on annual insecticide spraying of homes, which is expensive, damaging to the environment, and has short lived effects. One collaborative intervention in Guatemala showed that targeted home improvements using local labour and materials greatly reduced levels of triatomine infestation in homes, and that improvements were sustained over time. The intervention also contributed to other health benefits, to local economic activity, and to a reduction in the use of substances that harm the environment. ${ }^{23}$

Nationwide Children's Hospital ${ }^{24}$

In partnership with Community Development for All People (CD4AP) and other groups in Columbus, the US state of Ohio developed an intervention to improve housing conditions in a neighbourhood that had been historically disadvantaged through systematic racial segregation and economic exclusion. Nationwide Children's Hospital provided over a quarter of the $\$ 22.6 \mathrm{~m}$ investment from community partners, and CD4AP brought strong representation from residents, many of whom were patients of Nationwide, to the development of the intervention.

Together, the partnership renovated buildings, developed new housing, and created programmes to ensure affordability for renters.

Early outcomes include a reduction in vacancy rate (the chief concern of residents) from over $25 \%$ to $6 \%$, and associated increases in rates of graduation and decreases in homicides, with additional improvements in health expected over the long term. ${ }^{24}$

\section{Conclusion}

In his 1981 essay, "Solving for Pattern," ${ }^{25}$ the writer and social and environmental activist Wendell Berry discussed a remarkably similar challenge to the one we currently face in healthcare. He noted that although industrial methods had solved some of the problems of food production, they had produced "side effects" so damaging that they threatened the survival of farming. He proposed that farmers and others focus on a solution that was biological and not industrial-a solution that recognised the planet as an interdependent whole.

Organisations have a responsibility to society and the environment that goes beyond their primary purpose, and the healthcare sector is no different. Given the different ways that healthcare organisations affect health, we should pursue a triple aim of healthy people, living in equitable and resilient communities, on a sustainable planet. The examples presented here show that it is possible.

\section{Key messages}

Social inequity and environmental damage cost many lives and cause substantial ill health

The healthcare sector contributes to these harms, undermining its efforts to improve health

To reverse these harmful effects, healthcare practitioners and organisations must adopt a broader aim of healthy people, living in equitable and resilient communities, on a sustainable planet.

Examples show the power of the healthcare sector to achieve results on all three levels

We thank fellow attendees at the Salzburg Global Seminar "building healthy communities: the role of hospitals," including John Edgar, who is among the leaders of the work described in Columbus, Ohio. We also acknowledge Tyler Norris and Jeff Thompson, who contributed ideas and provided feedback on earlier versions.

Contributors and sources: DF advises healthcare organisations on interventions to address social determinants of health at the individual and community level. GC leads a global coalition of healthcare organisations to improve environmental health worldwide and in the communities they serve. JB has studied and reported widely on population health and health equity initiatives, and leads research and educational activities for a national network of hospitals. CB leads sustainability efforts for a local health authority. MD has studied and reported widely on issues related to healthcare administration, and provides leadership to an ambulatory care centre. GS directs a social innovation unit in a local health authority. DF and GC co-developed early drafts of the manuscript, and DF was responsible for the final draft based on working group discussions. Other authors contributed to further content and revisions. DF serves as guarantor.

Competing interests: We have read and understood BMJ policy on declaration of interests and have no relevant interests to declare.

Provenance and peer review: Commissioned; externally peer reviewed.

This article is part of a series from the Salzburg Global Seminar on building healthy communities: the role of hospitals. Open access fees were funded by the Robert Wood Johnson Foundation. The BMJ peer reviewed, edited, and made the decision to publish the article with no involvement from the foundation.

1 World Health Organization. Monitoring health for the SDGs: sustainable development goals. WHO, 2016.

2 Chung JW, Meltzer DO. Estimate of the carbon footprint of the US health care sector. JAMA 2009:302:1970-2. 10.1001/jama.2009.1610 19903917

3 Sustainable Development Unit. Carbon footprint update for NHS in England, 2015. NHS, 2016. https://www.sduhealth.org.uk/policy-strategy/reporting/nhs-carbon-footprint.aspx

4 Irwin A, Scali E. Action on the social determinants of health: a historical perspective. Glob Public Health 2007;2:235-56. 10.1080/17441690601106304 19283626

5 Consolandi C, Eccles RG. Supporting sustainable development goals is easier than you might think. MIT Sloan Management Review 2018 Feb 15. https://sloanreview.mit.edu/ article/supporting-sustainable-development-goals-is-easier-than-you-might-think/

6 Hallegatte S. Shock waves: managing the impacts of climate change on poverty. The World Bank, 2016.

7 Carleton T, Delgado M, Greenstone M, et al. Valuing the global mortality consequences of climate change accounting for adaptation costs and benefits. University of Chicago, Becker Friedman Institute for Economics Working Paper No 2018-51. 2018. https://www. ssrn.com/abstract=3224365

8 World Bank. Diagnostic assessment of select environmental challenges: an analysis of physical and monetary losses of environmental health and natural resources. World Bank, 2013:82.

9 Eckelman MJ, Sherman J. Environmental impacts of the US health care system and effects on public health. PLoS One 2016:11:e0157014

10.1371/journal.pone. 015701427280706

10 Kaplan S, Sadler B, Little K, Franz C, Orris P. Can sustainable hospitals help bend the health care cost curve? Issue Brief (Commonw Fund) 2012;29:1-14.23214181

11 Thompson J, Allen M. Going green in healthcare. With its energy-saving initiatives, Gundersen Health System has become energy independent. Healthc Exec 2015;30:62, 64-5.26742344

12 Eriksen J, Gustafsson LL, Ateva K, etal. Stockholm DTC. High adherence to the 'Wise List' treatment recommendations in Stockholm: a 15-year retrospective review of a multifaceted approach promoting rational use of medicines. BMJ Open 2017;7:e014345. 10.1136/bmjopen-2016-014345 28465306

13 Sharma S. NZ communities find unique way to re-use Rumala Sahib. Indian Weekender 2017 Dec 1. https://www.indianweekender.co.nz/Pages/ArticleDetails/7/8907/New-Zealand/ NZ-communities-find-unique-way-to-re-use-Rumala-Sahib

14 Damalas CA, Koutroubas SD. Farmers' exposure to pesticides: toxicity types and ways of prevention. Toxics 2016;4:E1. 10.3390/toxics4010001 29051407

15 Department of Health. Age UK. Compliance with hospital food standards in the NHS. 2017. https://assets.publishing.service.gov.uk/government/uploads/system/uploads attachment data/file/586490/HFSP Report.pdf

16 Winston CP, Sallis JF, Swartz MD, Hoelscher DM, Peskin MF. Consumer nutrition environments of hospitals: an exploratory analysis using the hospital nutrition environment scan for cafeterias, vending machines, and gift shops, 2012. Prev Chronic Dis 2013;10:E110. 10.5888/pcd10.120335 23823699

17 Cioci G, Hernandez Olivan P, Pinzauti I. Fresh, healthy, and sustainable food: best practices in European healthcare. Health Care Without Harm Europe; 2016. https://noharmeurope.org/sites/default/files/documents-files/4680/HCWHEurope_Food_Report_Dec2016. pdf

18 Ezeh A, Oyebode O, Satterthwaite D, etal . The history, geography, and sociology of slums and the health problems of people who live in slums. Lancet 2017;389:547-58. 10.1016/S0140-6736(16)31650-6 27760703

19 World Health Organization. International workshop on housing health and climate change: developing guidance for health protection in the built environment-mitigation and adaptation responses. WHO, 2010.

20 Gauld R, Blank R, Burgers J, etal . The world health report 2008. Primary healthcare: how wide is the gap between its agenda and implementation in 12 high-income health systems? Healthc Policy 2012;7:38-58. 10.12927/hcpol.2013.22778 23372580

21 Gomez M, Reddy AL, Dixon SL, Wilson J, Jacobs DE. A cost-benefit analysis of a state-funded healthy homes program for residents with asthma: findings from the New York State healthy neighborhoods program. J Public Health Manag Pract 2017;23:229-38. 10.1097/PHH.0000000000000528 28121775

22 Hospitals Aligned for Healthy Communities. Toolkit to help hospitals and health systems build community wealth through inclusive hiring, investment, and purchasing. https:// hospitaltoolkits.org/

23 Lucero DE, Morrissey LA, Rizzo DM, etal . Ecohealth interventions limit triatomine reinfestation following insecticide spraying in La Brea, Guatemala. Am J Trop Med Hyg 2013;88:630-7. 10.4269/ajtmh.12-0448 23382173

24 Kelleher K, Reece J, Sandel M. The healthy neighborhood, healthy families initiative. Pediatrics 2018;142:e20180261. 10.1542/peds.2018-0261 30076188

25 Berry W. The gift of good land: further essays, cultural and agricultural. Counterpoint, 1981. 
Published by the BMJ Publishing Group Limited. For permission to use (where not already granted under a licence) please go to http://group.bmj.com/group/rights-licensing/ permissionsThis is an Open Access article distributed in accordance with the Creative

Commons Attribution Non Commercial (CC BY-NC 4.0) license, which permits others to distribute, remix, adapt, build upon this work non-commercially, and license their derivative works on different terms, provided the original work is properly cited and the use is non-commercial. See: http://creativecommons.org/licenses/by-nc/4.0/. 